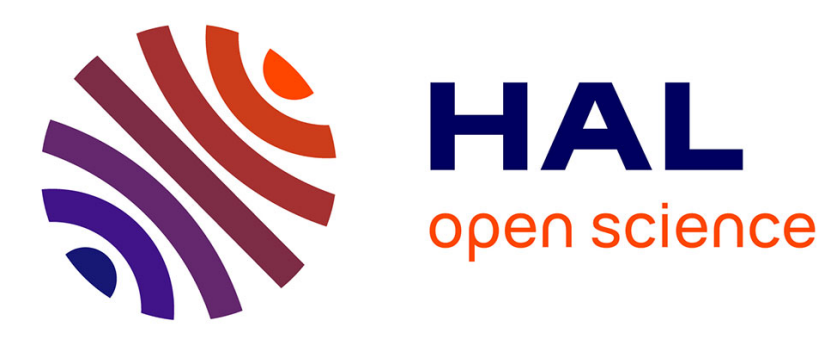

\title{
A quantitative analysis of health, safety and environment policy in France
}

Thomas Audiffren, Jean-Marc Rallo, Franck Guarnieri, Christophe Martin

\section{To cite this version:}

Thomas Audiffren, Jean-Marc Rallo, Franck Guarnieri, Christophe Martin. A quantitative analysis of health, safety and environment policy in France. 22nd European Safety and Reliability Conference - ESREL 2013, Sep 2013, Amsterdam, Netherlands. 8 p. - ISBN 9781138001237. hal-00869988

\section{HAL Id: hal-00869988 \\ https://hal-mines-paristech.archives-ouvertes.fr/hal-00869988}

Submitted on 28 Oct 2013

HAL is a multi-disciplinary open access archive for the deposit and dissemination of scientific research documents, whether they are published or not. The documents may come from teaching and research institutions in France or abroad, or from public or private research centers.
L'archive ouverte pluridisciplinaire HAL, est destinée au dépôt et à la diffusion de documents scientifiques de niveau recherche, publiés ou non, émanant des établissements d'enseignement et de recherche français ou étrangers, des laboratoires publics ou privés. 


\title{
A quantitative analysis of health, safety and environment policy in France
}

\author{
Thomas Audiffren $^{\mathrm{a}}$, Jean-Marc Rallo ${ }^{\mathrm{b}}$, Franck Guarnieri ${ }^{\mathrm{a}}$, Christophe Martin ${ }^{\mathrm{a}}$ \\ ${ }^{a}$ Mines ParisTech, Center for Research on Risks and Crises, Sophia-Antipolis, France \\ ${ }^{\mathrm{b}}$ Preventeo Le Cannet, France
}

\begin{abstract}
In June 2012, new legislation was introduced in France to regulate the role of occupational risk prevention specialists (OHS professionals). The fact that the legislature took an interest in this group of workers highlights their importance in the implementation of risk prevention policies in the workplace. However, it must be noted that knowledge of the risk prevention 'profession' remains limited. Moreover, this lack of knowledge makes it difficult to establish a true picture of their responsibilities for risk assessment and to accurately identify current practices used to manage occupational risks (work-related accidents, occupational illness, etc.).
\end{abstract}

In order to better understand the role of OHS professionals and the challenges they face the Centre for Risks and Crises at Mines ParisTech, working in collaboration with two privatesector health, safety and environment (HSE) companies ran a wide-ranging quantitative survey of 803 active OHS professionals. This survey had three key objectives. The first was to better understand the aims of OHS professionals and the kind of organization they work for. The second focused on an analysis of the brakes and obstacles they face, particularly with respect to their company's (managers and other employees) perception of the importance that should be given to the profession. The third and final objective was to identify the resources used by OHS professionals to manage issues related to the implementation of occupational risk prevention policy.

This article is in four parts. The first two parts describe the challenges encountered in developing the quantitative survey and the methodology used in its implementation. The third and fourth parts present the principal results.

Keywords: Occupational health and safety, quantitative survey, OHS professionals, HSE policy

\section{INTRODUCTION}

The implementation of an Occupational Health and Safety (OHS) management policy in business implies the mobilisation of key internal actors, namely OHS professionals. In June 2012, French legislation was implemented to formalise their role (Act No. 2011-867 of 20 July, 2011 [1]). The introduction of specific legislation highlights the importance of the role of OHS professionals in occupational risk management in the workplace. [2] However, a review of the literature concerning this population clearly shows that knowledge of the profession is very limited, if it exists at all.

To address this gap, the Centre for Research on Risks and Crises (CRC) of MINES ParisTech in partnership with two private sector companies (PREVENTEO and AFNOR) launched a wide-ranging quantitative survey [3]. Consequently, 803 OHS professionals were interviewed by telephone. The purpose of the exercise was to both better understand the actors themselves and also the determinants, perceptions and barriers to the implementation of an occupational risk prevention policy in the workplace. This article summarizes the results of the investigation. 
The article is divided into four parts. It begins with a brief overview of the methodology used in the quantitative survey (part 2) and then describes the typology of OHS professionals that was identified (part 3). It goes on to describe the determinants, perceptions and barriers associated with an HSE prevention policy (part 4) before returning to some particular difficulties in the tools used by OHS professionals (part 5).

\section{METHODOLOGY}

The survey collected data from more than 800 OHS professionals. It was executed in four distinct phases. These included planning, preparation of the questionnaire, its administration by telephone and finally the processing and analysis of results. The following sections describe each of these phases in detail.

\subsection{Phase 1: Planning}

The planning phase was based on a literature review that focused on the concepts of the "OHS professional" and "prevention policy". The key purpose was to identify the major issues and consequently decide the major themes to be addressed. The literature review led to the identification of numerous articles describing the difficulties encountered by companies in managing HSE regulatory compliance [4].

\subsection{Phase 2: Preparation}

Once phase 1 was completed the second preparatory phase could begin. An initial prototype questionnaire was drawn up by a working group from MINES ParisTech. This was followed by internal validation within the research laboratory. Following several rounds of internal validation and correction, the prototype was sent to an OHS expert and other experts working in industry for in-depth validation. The final version was then calibrated by an expert in statistics. The aim of this last step was simply to reformulate the questionnaire to facilitate statistical processing.

\subsection{Phase 3: Administration}

Before beginning wide-scale deployment to the full set of respondents, the questionnaire was tested by telephone on a sample of ten OHS professionals. This step led to some final adjustments in the wording to facilitate the administration of the survey. The final version of the questionnaire was then administered by telephone to $803 \mathrm{OHS}$ professionals in the period 20 October - 10 December 2008. Interviews lasted an average of 30 minutes (quite long for this type of survey). Figure 1 shows the distribution of respondents according to company sector. 


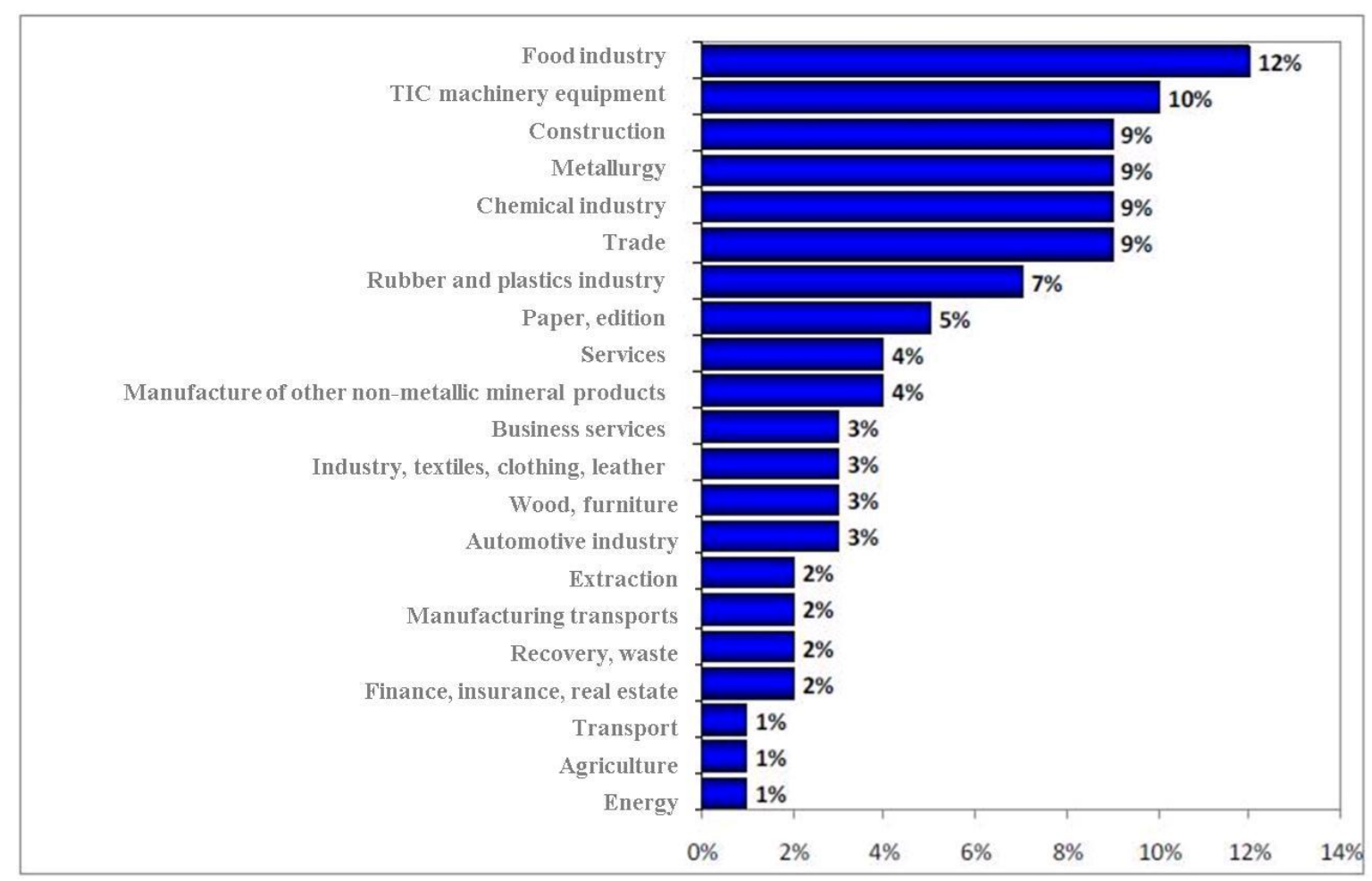

Figure 1: Distribution of the sample by industry

\subsection{Phase 4: Processing and presentation of results}

The raw data from the telephone survey was then processed. The initial dataset was not particularly useful in itself and it was necessary to use data analysis techniques such as multiple correspondence analysis (MCA) [5] and k-means cluster analysis [6].

The qualitative approach to data processing had the particular advantage of enriching the results and led to the development of a typology of OHS professionals. This typology is presented in the next section.

\section{A TYPOLOGY OF OHS PROFESSIONALS}

Initial results identified the characteristics of the population of OHS professionals more clearly. The typology could be divided into three distinct categories. The first concerns $O H S$ managers. The second groups OHS fieldworkers and the third concerns HSE officers. Occupational categories were based on a study by the French National Institute for Research and Safety (Institut national de recherché et de sécurité) published in June 2004 [7].

\subsection{Type 1: OHS managers}

The first type consists of so-called OHS managers. OHS managers represented $60 \%$ of the sample and they were primarily responsible for Health, Safety and Environment (HSE), Quality, Safety and Environment (QSE), Environmental Safety (ES) and Quality, Health, Safety and Environment (QHSE). They were typically employed in a general managerial role or worked directly with the company owner. Both their position and function tended to be a fairly recent development in the company. These actors have an important supervisory role and manage a budget dedicated to occupational risk prevention policy. Although they are usually highly educated it is unusual for them to have undertaken specific HSE training. 
The OHS fieldworker is the second type of OHS professional identified by the survey and represented only $18 \%$ of the sample. Members of this group usually have the job title "safety officer" and are found in operational roles. Typically, both their position and function is wellestablished in the company. They rarely manage a dedicated budget. Unlike OHS managers, fieldworkers usually lack academic qualifications but have undertaken specific HSE training.

\subsection{Type 3: HSE officers}

The third and final type identified concerns HSE officers. This group often has the job title of HSE, QSE or safety coordinators or facilitators. Typically they are new to the job, do not have a supervisory role and do not manage any risk prevention budget. They represented $22 \%$ of the sample and resembled the fieldworker in terms of education and training. Like fieldworkers, they have also undertaken specific HSE training and have an intermediate to low level of initial education.

In general, it should be noted that there is no relationship between the typology of OHS professionals and that of the companies studied. This is consistent with the observation that the OHS profession is poorly codified and very heterogeneous. For example, it is possible to find an OHS manager in both a very large certified company and a very small business.

The following section discusses the determinants, perceptions and barriers often associated with HSE prevention policy.

\section{DETERMINANTS, PERCEPTIONS AND OBSTACLES ASSOCIATED WITH THE IMPLEMENTATION OF PREVENTION POLICY}

A multiple correspondence analysis (MCA) of the composite variables of company prevention policy highlighted some key elements related to the success (or failure) of policy.

\subsection{Determinants of occupational risk prevention policy}

The results of the survey confirmed observations from other studies [8]. It appears that company size plays an important role in the implementation of prevention policy. The bigger the company, the more sophisticated the prevention policy. In addition, belonging to a highly regulated industry or an international group favours the existence of an HSE culture. In contrast, the survey suggested that industrial sector (textiles, metallurgy, construction, etc.) played a much more limited role.

\subsection{Companies' perceptions of the role of the OHS professional}

There is a widespread perception that the role of the OHS professional is to generate obligations or brakes on production that affect the overall economic performance of the company. The econometric results of the survey showed that this belief is very deeply held in companies with low productivity, which depend heavily on outsourcing. It should also be noted that as the company ages the benefits of the role of the OHS professional are more appreciated. This last point is illustrated in Figure 2. 


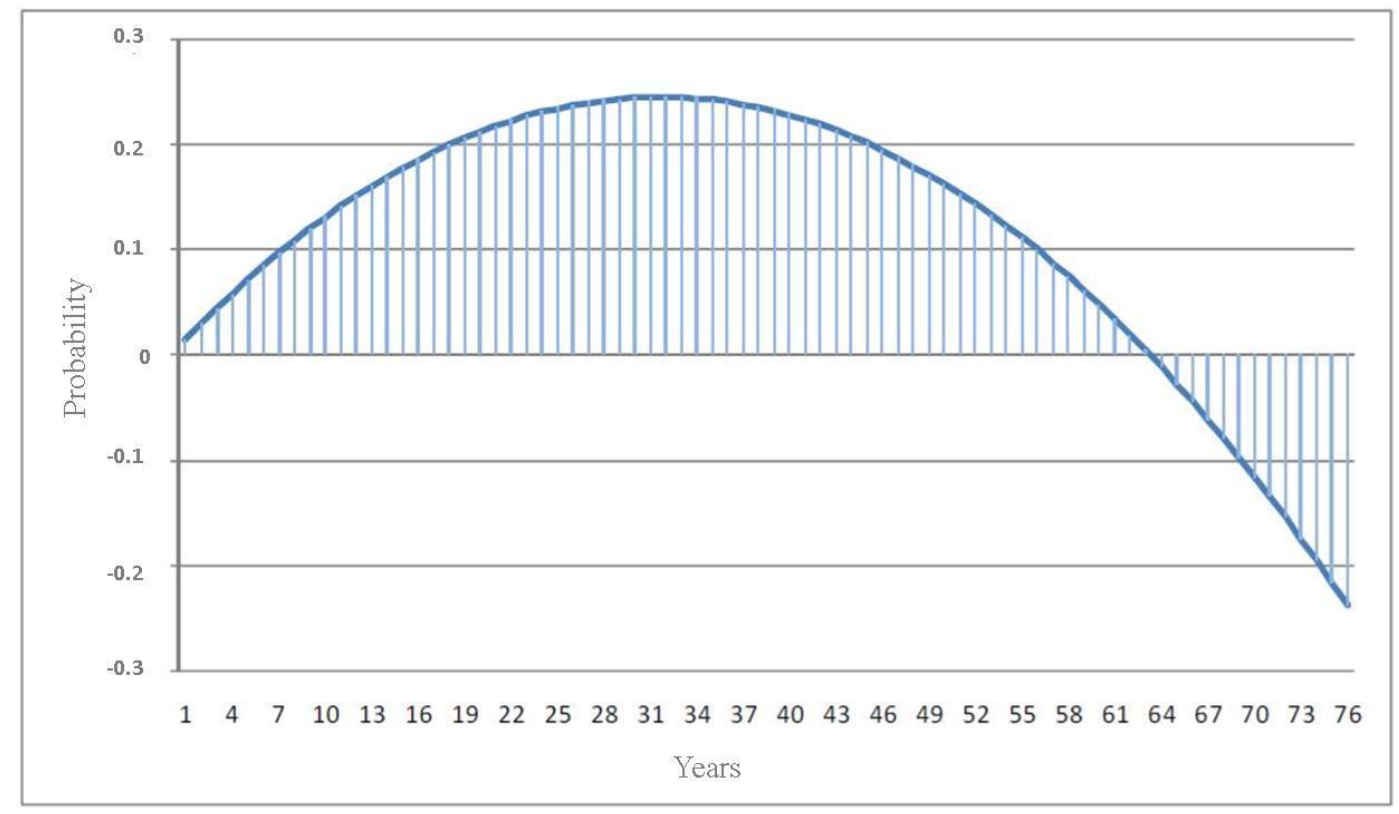

Figure 2: Probability that prevention policy is perceived as generating constraints that are at odds with company goals according to the age of the company

\subsection{Obstacles to the execution of an occupational risk prevention policy}

The survey also identified a typology of companies. Four types of companies were identified, ranging from the large certified company to the independent, non-certified small business. Seven obstacles to the execution of an occupational risk prevention policy were identified (time constraints, resistance to change, conflicting objectives, etc.). The survey showed that larger companies often find themselves facing all these obstacles. Conversely, smaller companies are essentially faced with the problem of resistance to change. Figure 3 shows the survey results related to the obstacles to the execution of prevention policy for large, certified companies.

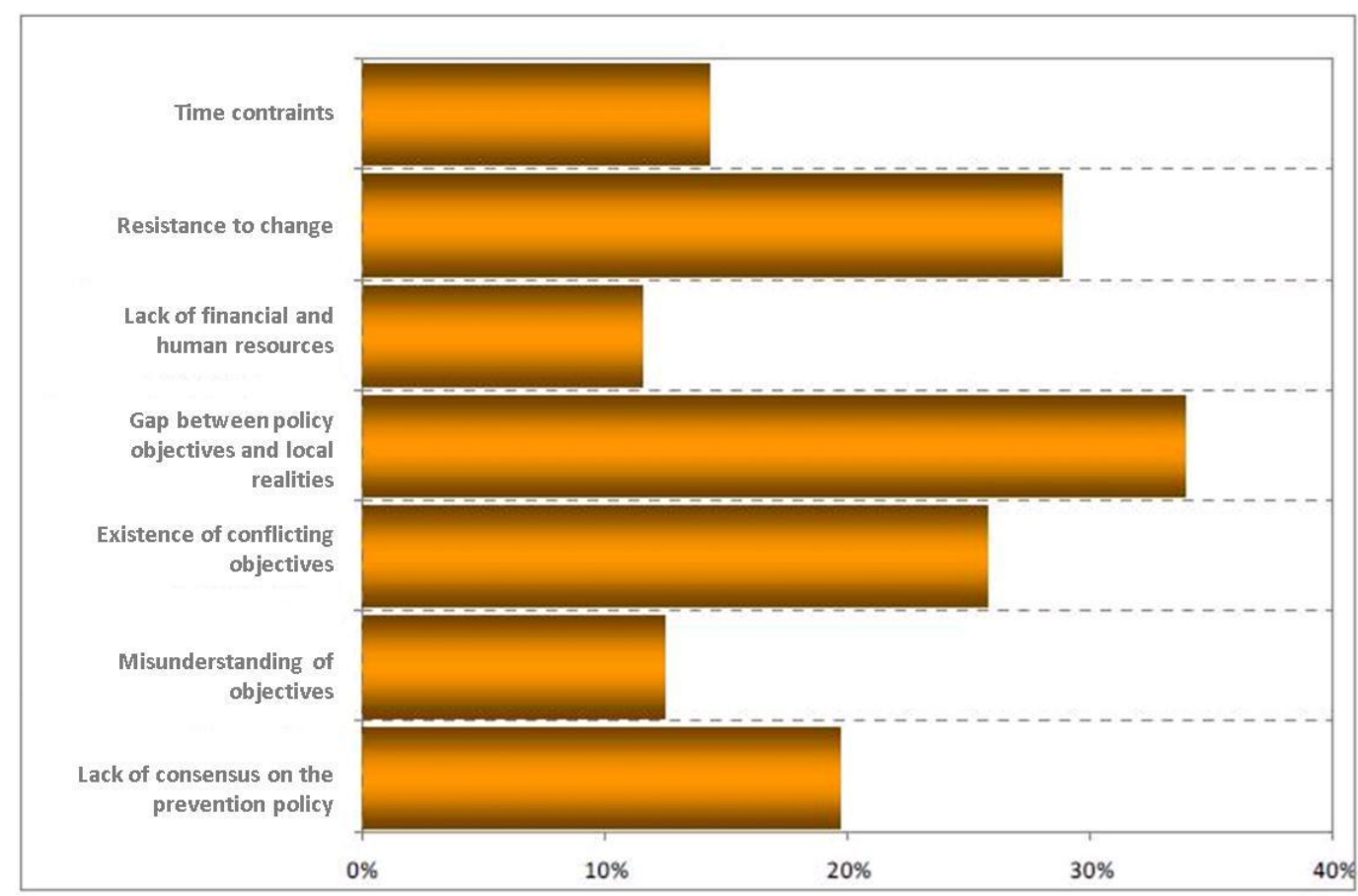


Figure 3: Obstacles to the execution of prevention policy in large, certified companies

\section{PROBLEMS ENCOUNTERED AND TOOLS USED BY OHS PROFESSIONALS}

In general terms, the survey showed that OHS professionals encountered difficulties such as raising staff awareness (45\%), lack of time (21\%), lack of human and financial resources $(16 \%)$, production constraints $(12 \%)$ or, to a lesser extent, lack of managerial commitment (7\%). In addition there were several more specific problems.

\subsection{Problems faced by OHS professionals}

The 803 OHS professionals surveyed said that in addition to raising staff awareness, their main difficulties related to the management of regulatory compliance and the execution and management of the occupational risk analysis (known as the document unique in France). In practice, regulatory monitoring is very time-consuming and difficult for OHS professionals. Risk analysis is similarly time-consuming but a second problem is the ongoing inadequacy of available tools (the main tools used are classical office software such as Excel®, Word, etc.). To a lesser extent, OHS professionals emphasized difficulties related to the management of safety indicators (frequency, severity, etc.), relations with bodies representing employees and interactions with occupational health services. Figure 4 summarizes the list of obstacles encountered by OHS professionals.

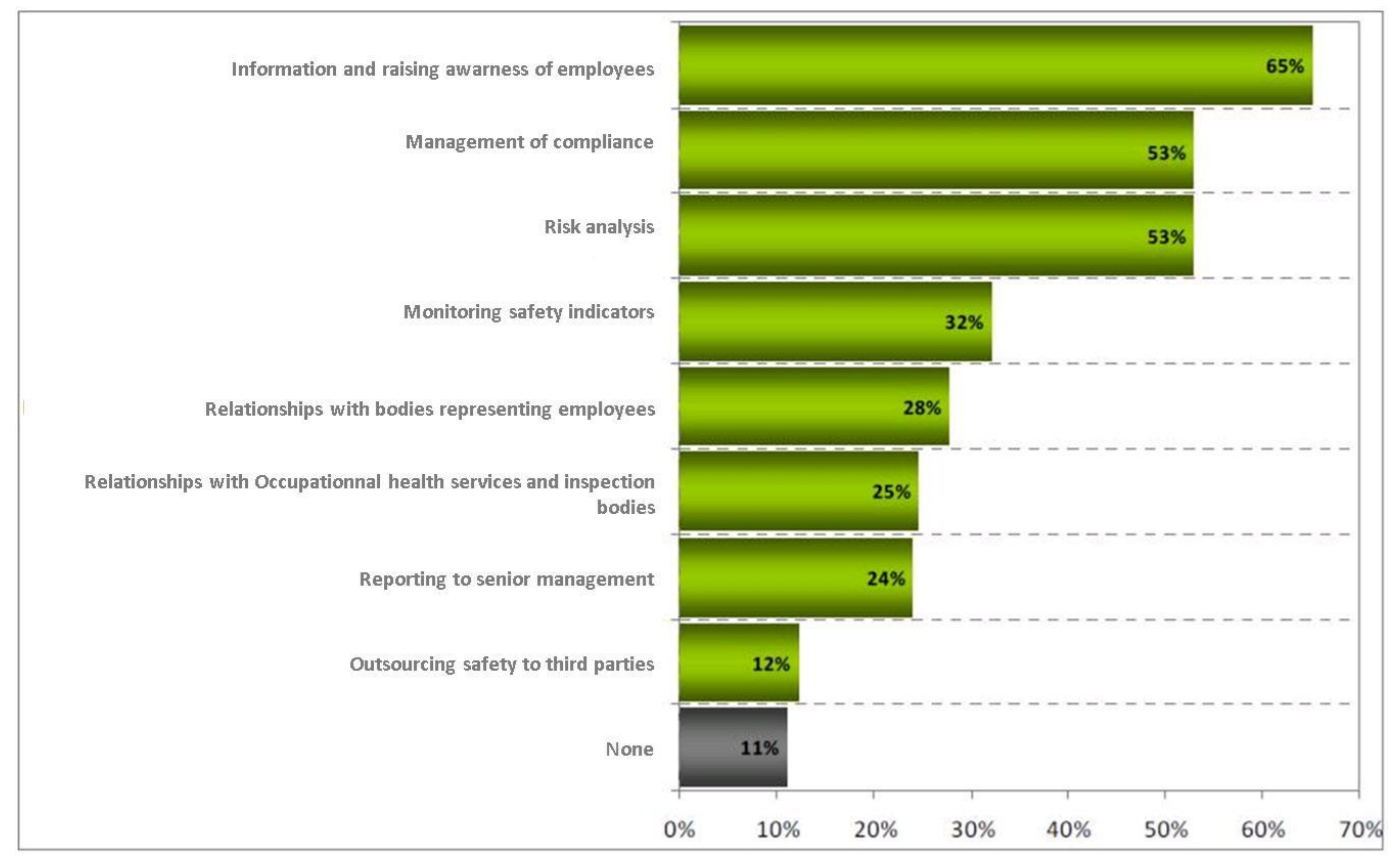

Figure 4: Current problems faced by OHS professionals

\subsection{Tools used by OHS professionals}

Training tools are primarily used in information campaigns and to raise the awareness of employees. On another note, OHS professionals make use of information freely available on the internet to deal with problems related to the management of regulatory compliance and risk analysis. It also appears that although they often draw upon the expertise of consultants and databases to manage compliance, specialized risk management software is relatively unused. At the time the survey was carried out, there seemed to be few tools available to help OHS professionals either to efficiently manage indicators or to facilitate relations with 
management, bodies representing workers or occupational health services. There is a clear need for specific tools to respond to these issues.

\section{CONCLUSION}

Although this article only offers an extremely partial summary of the survey, it nevertheless lifts the veil on various important issues. First, the role of the OHS professional encompasses many heterogeneous situations and it seems that the trend towards a positive perception of the profession is directly related to the age of the company. Furthermore, we note that negative perceptions and obstacles significantly increased the difficulties faced by OHS professionals. Such issues delay the implementation of a truly effective occupational risk prevention policy.

Finally, the major problems faced by OHS professionals concern raising the awareness of the workforce, management of regulatory compliance and implementation of an appropriate risk analysis. To cope with these challenges, they primarily use training tools, databases and external consultants. At the same time, the relative neglect of specialized software is worrying as these tools can be very useful in structuring a comprehensive prevention policy that can integrate occupational, environmental, industrial, health or other types of risk [9]. In order to develop this point in greater detail, a second quantitative survey was launched by MINES ParisTech, PREVENTEO and AFNOR in 2010. This second survey addressed business practices related to risk management and HSE compliance and the benefits and limitations of the certification process.

\section{REFERENCES}

[1] Law n²011-867 of 20 July 2011 concerning the role of the occupational physician.

[2] Cambon J, Guarnieri F, Groeneweg J, Towards a new tool for measuring Safety Management Systems performance, Proceedings 2nd Symposium on Resilience Engineering, 2006, 2nd Symposium on Resilience Engineering (2006-11-08), Edited by Presses des Mines (France).

[3] Guarnieri F, Miotti H, Martin C, Besnard D, Rallo JM, Occupational safety and health in France : Practitioners and policy, Edited by AFNOR Group, November 2010.

[4] Audiffren T, Contribution à la maîtrise des conformités légales en santé et sécurité au travail, Thèse MINES ParisTech, Centre de recherche sur les Risques et les Crises (CRC), Décembre 2012.

[5] Greenacre MJ, Correspondence Analysis in Practice, $2^{\text {nd }}$ edition, Academic Press, London, 2007.

[6] Arabie P, Hubert LJ, De Soete G, Clustering and Classification, World Scientific, Singapore, 1999.

[7] Garrigou A, Peissel-Cottenaz G, Contribution à la découverte des préventeurs et à la caractérisation de leurs besoins en formation continue, Note scientifique et technique NS 244, Institut National de Recherche et de Sécurité (INRS), June 2004.

[8] Guarnieri F, Martin C, Pratiques et prévention des risques professionnels dans les PMEPMI, Editions Lavoisier, Paris, 2008. 
[9] Bourreau L, Audiffren T, Rallo JM, Guarnieri F, Industrial maintenance in the gas sector: the contribution of knowledge bases to compliance evaluation, ESREL Conference 2012, Helsinki, Finland, June 2012. 